\title{
Exceptional antioxidant, non-cytotoxic activity of integral lemon pectin from hydrodynamic cavitation
}

\author{
Domenico Nuzzo, ${ }^{[a]}$ Laura Cristaldi, ${ }^{[a]}$ Marzia Sciortino, ${ }^{[b]}$ Lorenzo Albanese, ${ }^{[c]}$ Antonino Scurria, ${ }^{[b]}$ \\ Federica Zabini, ${ }^{[c]}$ Claudia Lino, ${ }^{[b]}$ Mario Pagliaro, ${ }^{[b]}$ Francesco Meneguzzo, ${ }^{[c] *}$ Marta Di Carlo, ${ }^{[a] *}$ \\ Rosaria Ciriminna ${ }^{[b] *}$
}

\begin{abstract}
Pectin integrally extracted with water-soluble phytochemicals from waste lemon peel via hydrodynamic cavitation in water directly at pre-industrial scale and further isolated via freeze drying shows exceptionally high antioxidant and non-cytotoxic activity. Preliminary investigation indicates also significant antimicrobial activity. These findings open the route to the development of new nutraceutical agents based on a new bioproduct easily obtained in large amounts from an abundant by-product of the agrofood industry.
\end{abstract}

Keywords: pectin; antioxidant; lemon; flavonoids; hydrocavitation

Pectin is the natural hydrocolloid most valued in the food industry where it is widely used as a stabilizing additive as well as to enhance the food textural properties [1]. Chiefly derived from lemon peel and apple pomace, as well as lately from orange peel, commercial pectin is industrially obtained through an hydrolytic process carried out with the aid of diluted mineral acids at relatively high temperatures [2].

Besides generating large amounts of effluents, the process invariably degrades the structure of pectin found in the fruit peel, lowering the molecular weight and partly also the degree of esterification (DE). For example, compared to sulphuric acid more expensive citric acid recovers pectin of higher molecular weight (improving the viscosity and the flow properties of pectin gel) from citrus fruit peels [3].

Perhaps not surprisingly, given its ubiquitous presence in fruits and vegetables, pectin is a prebiotic dietary fiber exerting multiple physiological and biological functions including

\footnotetext{
${ }^{*}$ Corresponding authors

[a] Dr D. Nuzzo, Dr L. Cristaldi, Dr M. Di Carlo Istituto per la Ricerca e I'Innovazione Biomedica, CNR via U. La Malfa 153

90146 Palermo (Italy)

E-mail: marta.dicarlo@irib.cnr.it

${ }^{[b]} \operatorname{Dr}$ R. Ciriminna, Dr M. Sciortino,

Dr A. Scurria, Dr C. Lino, Dr M. Pagliaro

Istituto per lo Studio dei Materiali Nanostrutturati, CNR

via U. La Malfa 153

90146 Palermo (Italy)

E-mail: rosaria.ciriminna@cnr.it

${ }^{[c]}$ Dr L. Albanese, Dr F. Zabini, Dr F. Meneguzzo

Istituto per la Bioeconomia, CNR

via Madonna del Piano 10

50019 Sesto Fiorentino FI (Italy)

E-mail: francesco.meneguzzo@cnr.it
}

significant anticancer, antiobesity and heavy metal-binding capacity, which make it increasingly used as an active ingredient by the pharmaceutical, nutraceutical and food industries [4].

From microwave-assisted extraction at high temperature $\left(110{ }^{\circ} \mathrm{C}\right)$ [5], through subcritical water extraction [6] and microwave hydrodistillation and gravity [7], several new acid-free extraction methods have shown to afford pectin of improved structural and functional properties on both laboratory and preindustrial scale.

Amid them, perhaps the most promising method from the industrial viewpoint is the extraction based on controlled hydrodynamic cavitation $(\mathrm{HC})$ [8]. Originally demonstrated in the citrus fruit field with waste orange peel on semi-industrial scale (42 kg of raw material in $142 \mathrm{~L}$ water) [9], the process quickly affords extraction and separation of water soluble and insoluble bioproducts with practically no degradation neither of pectin nor of the valued phytochemicals contained in the orange peel.

The orange pectin thereby obtained has a remarkably low degree of esterification $(17.05 \pm 0.60 \%)$, which is important because pectin with $\mathrm{DE}<50 \%$ does not require sugar or acidic conditions to gel, making it particularly well suited for food, pharmaceutical, and nutraceutical applications [10].

Extending now the hydrodynamic cavitation process to waste lemon peel (WLP) obtained from a lemon processing company, we smoothly isolated pectin from the liquid fraction resulting from the hydrocavitation process. Such pectin was colored in yellow, with a delicate fragrance pointing to the presence of lemon terpenes.

Along with a lemon pectin sample obtained after lyophilization, Figure 1 shows an image of the industrial lemon peel undergoing grinding in ice with a blender prior to the hydrocavitation-assisted extraction process. Such pretreatment was necessary for circulating the water-WLP mixture through the pump and the reactor, and could easily be performed automatically in an industrial-grade system.

The HC extraction device, including a closed hydraulic loop (total volume capacity around $230 \mathrm{~L}$ ), a centrifugal pump (Lowara, Vicenza, Italy, ESHE 50-160/ 75) with $7.5 \mathrm{~kW}$ nominal mechanical power and rotation speed of $2900 \mathrm{rpm}$, and a Venturi-shaped HC reactor, has been described in detail elsewhere [9]. The main structural difference with the extraction process applied to waste orange peel is that now the $\mathrm{HC}$ assisted extraction was carried out in a sealed reactor in order to minimize the loss of the lemon peel's volatile components. This was one of the recommendations arisen from the previous study describing the waste orange peel treatment [9]. 
In detail, $34 \mathrm{~kg}$ of fresh waste lemon peel obtained from organically grown Siracusa lemons (Citrus limon, cultivar 'femminello') by an in-line extractor at a juice factory kindly donated by a company (Campisi Citrus, Siracusa, Italy) were first grinded in ice with an electric blender and then added along with $120 \mathrm{~L}$ of tap water to the $\mathrm{HC}$ device. The reactor was sealed and cavitation started.
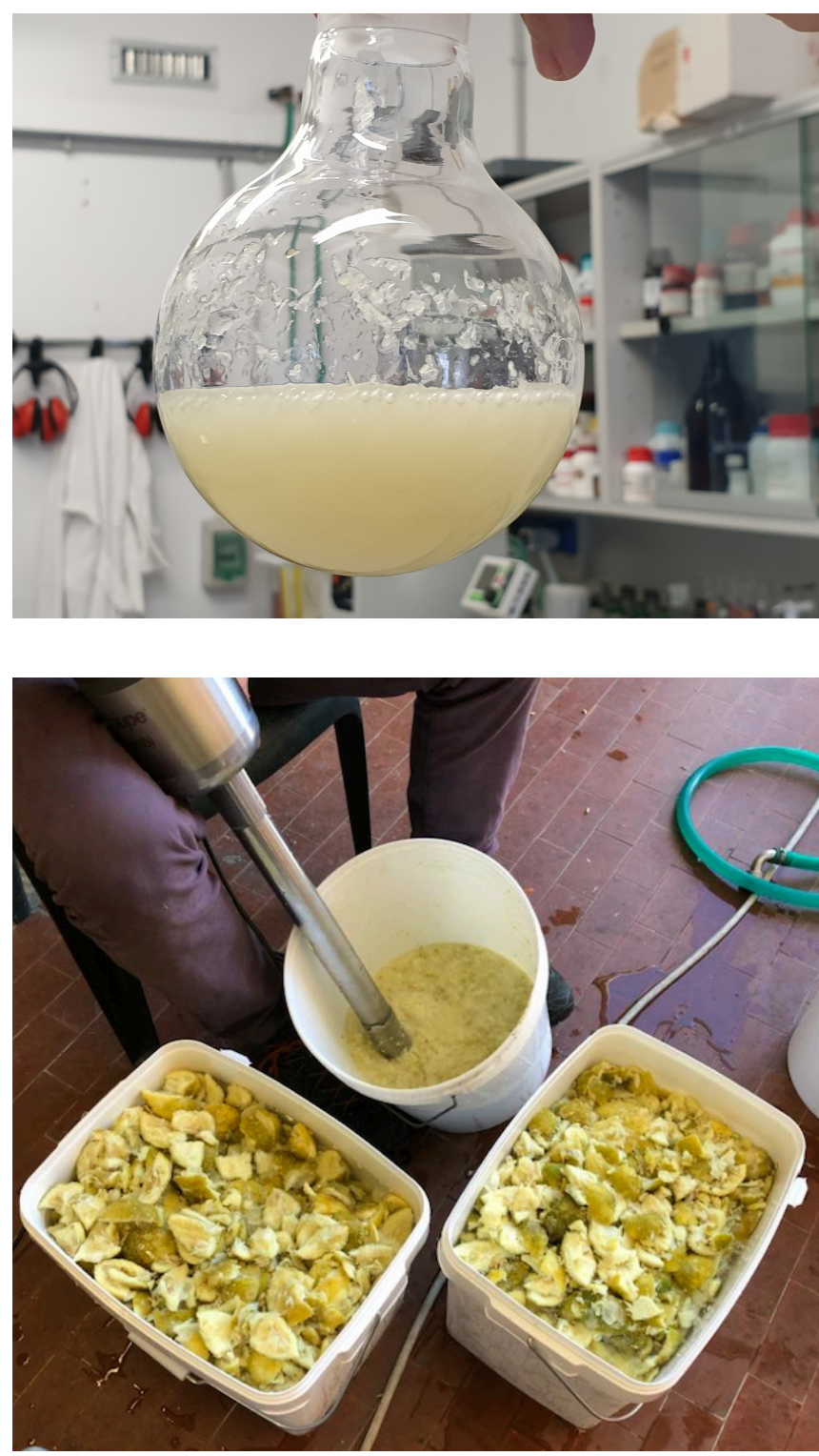

Figure 1. Lemon pectin obtained after freeze drying (top), and waste lemon peel undergoing grinding with a blender prior to the hydrocavitation-assisted extraction process (bottom)

The whole process lasted $60 \mathrm{~min}$ and consumed $6.70 \mathrm{kWh}$ of electric energy, thus the specific consumed energy was $0.22 \mathrm{kWh}$ per $\mathrm{kg}$ of fresh WLP. No forced heat dissipation was applied and the temperature rose from $10^{\circ} \mathrm{C}$ up to $42^{\circ} \mathrm{C}$ after $60 \mathrm{~min}$. After completion, the liquid phase was collected and sent for lyophilization. The lyophilization process, which lasted a few days, was carried out in parallel using several $250 \mathrm{~mL}$ balloons connected to the pump of a Labconco FreeZone 4.5 Liter benchtop freeze dry system. The yellow, perfumed pectin thereby obtained (Figure 1) was stable and retained its yellow color during storage at room temperature and in direct contact with air.

The HC-based citrus peel extraction is actually so effective [9], that virtually all water-soluble compounds are brought in solution. Furthermore, explaining the exquisite smell of the integral lemon pectin obtained we know from the waste orange peel experiment carried out under similar $\mathrm{HC}$ extraction conditions, that the citrus essential oil contained in the peel is emulsified in a ultrastable nanoemulsion dispersed in the aqueous phase [9]. Accordingly, we call Integro-Pectin (In-Pec) the integral pectin samples thereby obtained.

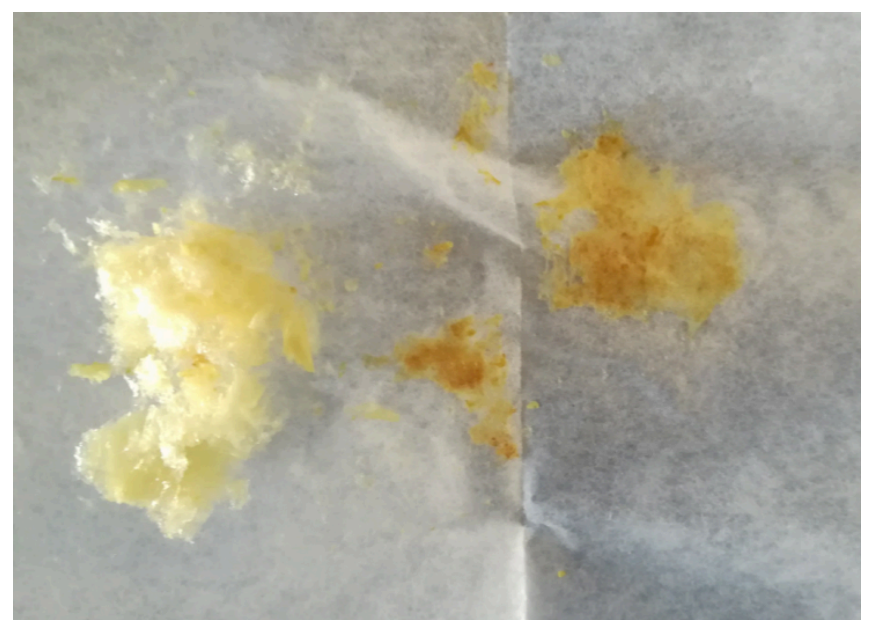

Figure 2. Integral lemon pectin obtained via hydrodynamic cavitation of waste lemon peel (Int-Pec, left), and after thermal treatment at $200^{\circ} \mathrm{C}$ for 5 min (Int$\mathrm{Pec}-\mathrm{Hs}$, right).

After dehydration, the product was pulverized and $100 \mathrm{mg}$ of this powder dissolved in $5 \mathrm{~mL}$ of phosphate-buffered saline (PBS) solution ( $\left.\mathrm{pH}=7.4 ; 137 \mathrm{mM} \mathrm{NaCl}, 2.7 \mathrm{mM} \mathrm{KCl}, 8 \mathrm{mM} \mathrm{Na}_{3} \mathrm{PO}_{4}\right)$. For the heat-stressed sample preparation, the In-Pec powder was exposed at $200^{\circ} \mathrm{C}$ for $5 \mathrm{~min}$. Figure 2 shows sample of both pectins.

An aliquot $(100 \mathrm{mg})$ of the resulting Integro-Pectin Heat Stressed (In-Pec-Hs) powder was dissolved in $5 \mathrm{~mL}$ of PBS $(\mathrm{pH}=7.4$; $137 \mathrm{mM} \mathrm{NaCl}, 2.7 \mathrm{mM} \mathrm{KCl}, 8 \mathrm{mM} \mathrm{Na}_{3} \mathrm{PO}_{4}$ ). The solutions were magnetically stirred for an hour and filtered by using a $0.45 \mu \mathrm{m}$ sartorius filter, aliquoted $(1 \mathrm{~mL} / \mathrm{vial})$, and stored at $-20^{\circ} \mathrm{C}$.

The total phenolic content was calculated according to an adapted Folin-Ciocalteu (F-C) colorimetric assay [11]. Aliquots $(0.2 \mathrm{~mL})$ of the $\mathrm{In}-\mathrm{Pec}$ and $\mathrm{In}-\mathrm{Pec}-\mathrm{Hs}$ were made up to $5 \mathrm{~mL}$ with distilled water, followed by addition of $0.5 \mathrm{~mL}$ of Folin-Ciocalteu reagent. After $3 \mathrm{~min}, 1 \mathrm{~mL}$ of $\mathrm{Na}_{2} \mathrm{CO}_{3}(20 \% \mathrm{w} / \mathrm{v})$ was added to each mixture subsequently made up to $10 \mathrm{~mL}$ with triple distilled water. The samples were then stored for $2 \mathrm{~h}$ at room temperature after which the absorbance of the solutions was measured at $765 \mathrm{~nm}$ by using a spectrophotometer (Shimadzu 
UV-2401 Dual-Beam UV-Vis). Quantification employed a gallic acid standard curve.

Results in Figure 2B point to high total phenolic content for both the Integro-Pectin (0.88 $\mathrm{mg} \mathrm{GAE} / \mathrm{g}$ ) and, though slight lower, for the heat-stressed derivative $(0.81 \mathrm{mg} \mathrm{GAE} / \mathrm{g})$.

The Oxygen Radical Absorbance Capacity ORAC assay was performed according to slightly modified published procedures [12]. The reaction was carried out by using a 96 -well plate: $160 \mu \mathrm{L}$ of $0.04 \mu \mathrm{M}$ fluorescein in $0.075 \mathrm{M} \mathrm{Na}$ K phosphate buffer $\mathrm{pH} 7.0,20 \mu \mathrm{L}$ of diluted phenolic extract, or $20 \mu \mathrm{L}$ of $100 \mu \mathrm{M}$ Trolox. The mixture was incubated for $10 \mathrm{~min}$ at $37^{\circ} \mathrm{C}$ in the dark. After incubation, $20 \mu \mathrm{L}$ of $40 \mathrm{mM}$ 2,2'-Azobis-(2methylpropionamidine) dihydrochloride (AAPH) solution was added. The microplate was immediately placed in a microplate reader (Thermo Scientific Fluoroskan Ascent F2 Microplate), and the fluorescence recorded (excitation and emission wavelengths at 485 and $527 \mathrm{~nm}$, respectively) every $5 \mathrm{~min}$ for $60 \mathrm{~min}$.

The ORAC value refers to the net area under the curve of fluorescein decay in the presence of the Klamin $®$ phenolic extract or Trolox, minus the blank area. The activity of the sample expressed in $\mu \mathrm{mol}$ of Trolox equivalents (TE) per $\mathrm{g}$ of In$\mathrm{Pec}$ or In-Pec-Hs by using equation (1):

$$
\text { ORAC }=k * a * h *\left[\left(S_{\text {sample }}-S_{\text {blank }}\right) /\left(S_{\text {Trolox }}-S_{\text {blank }}\right)\right]
$$

where $k$ is the final dilution of the water-soluble extract; $a$ is the ratio between the volume (in $\mathrm{L}$ ) of the water-soluble extract and the grams of In-Pec or In-Pec-Hs; $h$ is the final concentration of Trolox expressed as $\mu \mathrm{mol} / \mathrm{L}$; and $S$ is the area under the curve of fluorescein in the presence of sample, Trolox, or buffer (blank) solution. All reaction mixtures were prepared in triplicates, and at least three independent assays were performed for each sample.
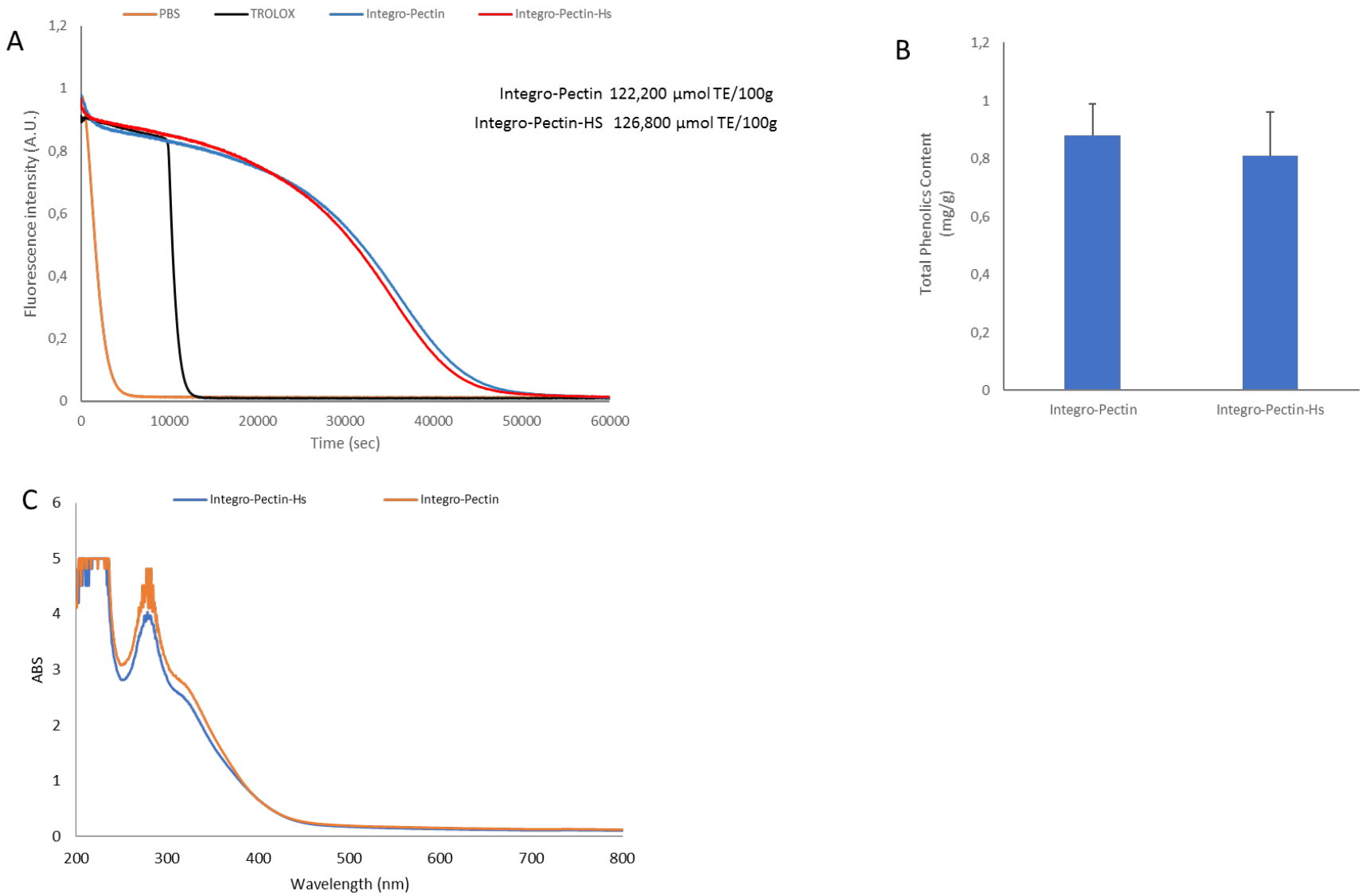

Figure 3. Antioxidant activity of In-Pec and In-Pec-Hs pectin samples, expressed as $\mu$ mol of Trolox equivalents (TE) per $100 \mathrm{~g}$ of pectin (ORAC assay, A); total phenolics content expressed $\mathrm{mg}$ of gallic acid equivalents per $\mathrm{g}$ of extract from the F-C assay (B); $\mathrm{U} V$-vis absorption spectra in the 200 to $800 \mathrm{~nm}$ range (C).

To test the antioxidant properties of Integro-Pectin, powders of In-Pec and In-Pec-Hs were dissolved in PBS and submitted to ORAC and Folin-Ciocalteu assays. The antioxidant activity of the pectin samples, expressed as $\mu \mathrm{mol}$ of Trolox equivalents (TE) per $\mathrm{g}$ of pectin for ORAC assays and as mg of gallic acid equivalents per $\mathrm{g}$ of extract for the $\mathrm{F}-\mathrm{C}$ assay is displayed in Figures $3 \mathrm{~A}$ and $3 \mathrm{~B}$, respectively.

The ORAC values are remarkably high for both Integro-Pectin $(122,200 \mu \mathrm{mol} \mathrm{TE} / 100 \mathrm{~g})$ and its heat-stressed derivative $(126,800 \mu \mathrm{mol} T E / 100 \mathrm{~g})$. For comparison, freeze-dried olive mill 
wastewater rich in olive polyphenols has an ORAC of 201,100 $\mu \mathrm{mol}$ TE/100g [13], and black raspberry fruit has $16,210 \mu \mathrm{mol}$ $\mathrm{TE} / 100 \mathrm{~g}$ (on a dry matter basis) [14].

For the toxicity assay, we used human epithelial cells of the A549 cell line widely employed as epithelial cell model for drug metabolism [15]. The cells were cultured with RPMI 1640 medium (Celbio, Milano, Italy) supplemented with $10 \%$ fetal bovine serum (FBS) (Gibco-Invitrogen, Milano, Italy), $2 \mathrm{mM} \mathrm{/-}$ glutamine (SIGMA-Aldrich, Italy), and $1 \%$ antibiotics (50 mg $\mathrm{mL}^{-1}$ penicillin and $50 \mathrm{mg} \mathrm{mL}{ }^{-1}$ streptomycin, Sigma-Aldrich, Italy). The cells were maintained in a humidified $5 \% \quad \mathrm{CO}_{2}$ atmosphere at $37 \pm 0.1^{\circ} \mathrm{C}$.

The A549 cells were then treated with $0.25,0.5$, and $1 \mathrm{mg} / \mathrm{mL}$ of In-Pec or In-Pec-Hs for $24 \mathrm{~h}$ or with tert-butyl hydroperoxide (TBH, a model for organic hydroperoxides formed in pathological conditions widely employed to study intact biological systems [16]), pure $(75 \mu \mathrm{M})$ or combined with In-Pec and In-Pec-Hs at different concentrations $(0.25,0.5$, and $1 \mathrm{mg} / \mathrm{mL})$ for $24 \mathrm{~h}$. Untreated A549 cells were used as control. An optical microscope (Zeiss Axio Scope) equipped with a camera (Axiocam) and $20 \times$ objectives, was utilized to analyze the morphology of the cells.

The cell viability was measured by the MTS assay (Promega Italia, Milano, Italy). In detail, $1 \times 10^{4} / \mathrm{ml}$ A549 cells were plated in 96 well plate. After $24 \mathrm{~h}$, these cells were untreated (control) or treated with In-Pec or In-Pec-Hs. The cell proliferation assay reagent MTS 3-(4,5-Dimethylthiazol-2-yl)-5-(3carboxymethoxyphenyl)-2-(4-sulfophenyl)-2H-tetrazolium was used according to the manufacturer's instructions. After cell treatments, a $20 \mu \mathrm{L}$ aliquot of the MTS solution was added to each well and incubated with the cells for $1 \mathrm{~h}$ at $37{ }^{\circ} \mathrm{C}, 5 \% \mathrm{CO}_{2}$. The absorbance at $490 \mathrm{~nm}$ was measured with the GloMax Discover Microplate Reader (Promega Italia, Milano, Italy). Results were expressed as the percentage of the MTS reduction with the control samples as reference and are presented as mean value \pm standard deviation (SD).

To assess the generation of Reactive Oxygen Species (ROS), the treated A549 cells were placed in a 96-well microplate. Some of A549 cells were treated with TBH $(75 \mu \mathrm{M})$ alone or in combination with either In-Pec or In-Pec-Hs for $24 \mathrm{~h}$. After that, a small aliquot of dichlorofluorescein diacetate (DCFH-DA) $(1 \mathrm{mM})$ was added to each sample, placing the dyed cell samples in the dark for $10 \mathrm{~min}$ at room temperature. After washing with PBS, the cells were analyzed by an Axio Scope 2 a fluorescence microscope (Zeiss, Oberkochen, Germany). The UV-vis absorption spectrum in the $200-800 \mathrm{~nm}$ range points to the presence of phytocomplexes as shown by peaks at $250 \mathrm{~nm}$ and $370 \mathrm{~nm}$ (Figure 2C).

The complete absence of cytotoxicity for both Integro-Pectin and heath-stressed Integro-Pectin-Hs is shown by full retention of cell viability after 24 incubation of different pectin concentrations added to A549 cells. The MTS assay (Figure 4A) shows that no toxicity was detected at all the utilized concentrations compared with the control. The result was confirmed by microscopic observation of cellular morphology in which correct cell shape was observed at any pectin concentration (Figure 4B) confirming the absence of any cell damage. 
A

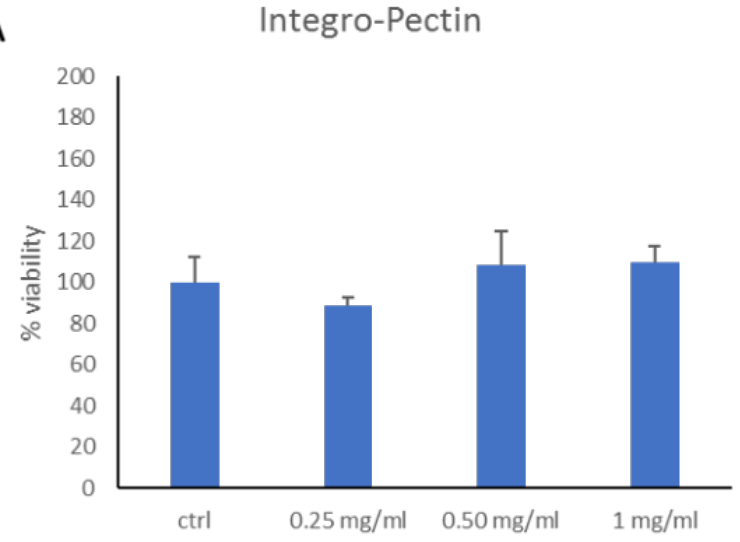

B

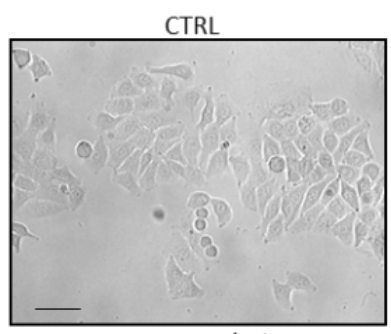

$0.50 \mathrm{mg} / \mathrm{ml}$
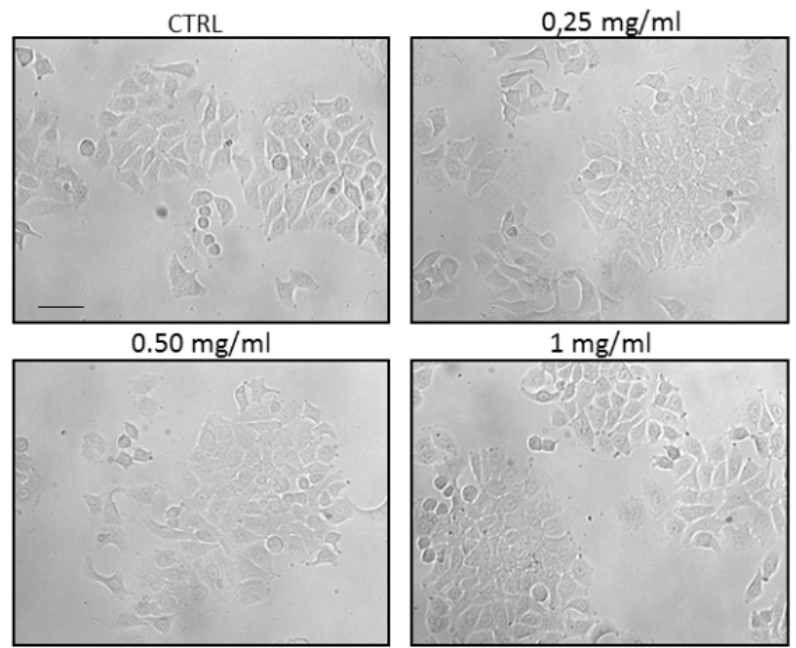

$1 \mathrm{mg} / \mathrm{ml}$

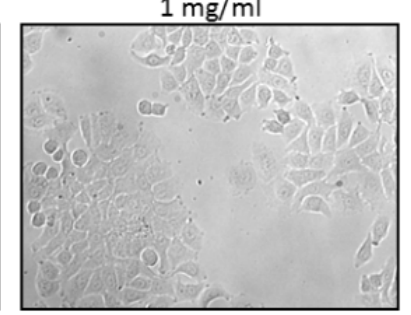

Integro-Pectin-Hs

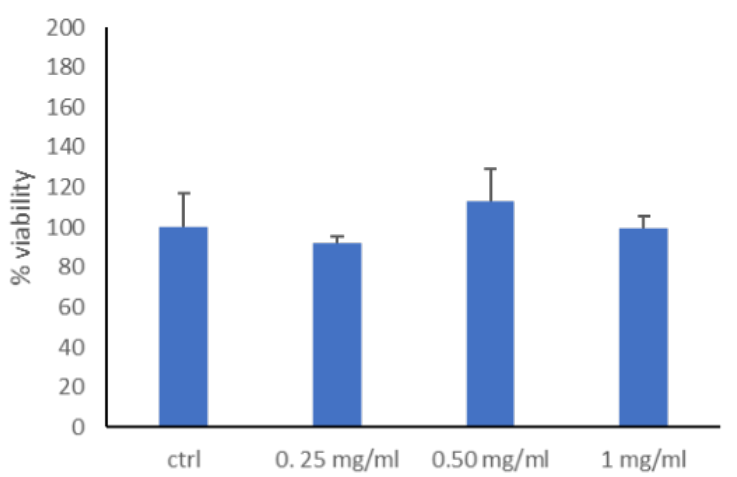

CTRL

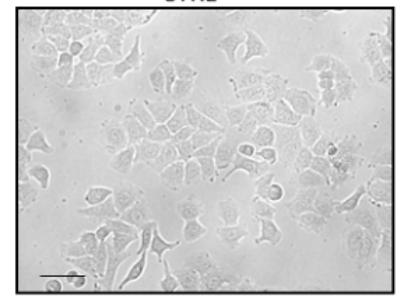

$0.50 \mathrm{mg} / \mathrm{ml}$

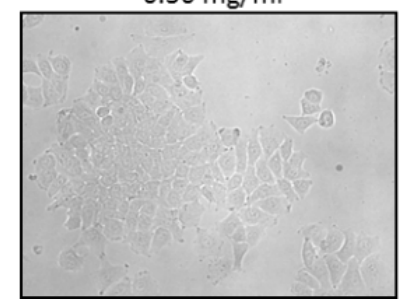

Figure 4. Cell viability at different integral pectin and heat-stressed pectin concentrations compared with control (A), and cellular morphology at different pectin concentrations compared with control $(B)$. Bar $=100 \mu \mathrm{m}$, Control $=$ CTRL.

Finally, as shown by the results of the dichloro-dihydrofluorescein diacetate (DCFH-DA) quantitative assay for oxidative stress assessment of treated cells, Integro-Pectin prevents oxidative stress (Figure 5). 
A
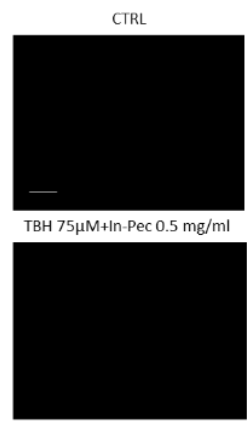

In-Pec $0.5 \mathrm{mg} / \mathrm{ml}$

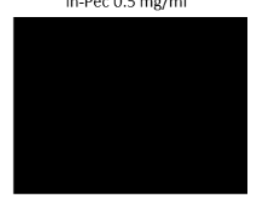

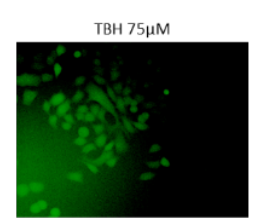

TBH $75 \mu \mathrm{M}+\mathrm{In}$-Pec-Hs $0.5 \mathrm{mg} / \mathrm{m}$

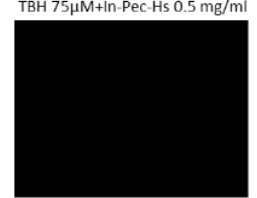

$\mid n-P e c-H s ~ 0.5 \mathrm{mg} / \mathrm{ml}$

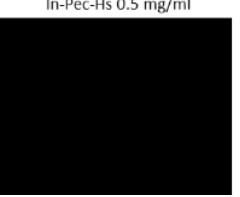

B

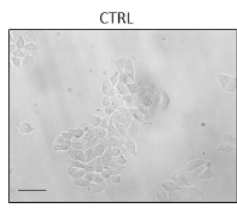

TBH $75 \mu \mathrm{M}+\mathrm{ln}-\mathrm{Pec} 0.5 \mathrm{mg} / \mathrm{ml}$

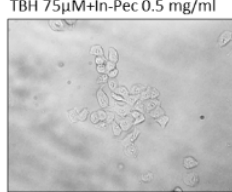

In-Pec $0.5 \mathrm{mg} / \mathrm{ml}$

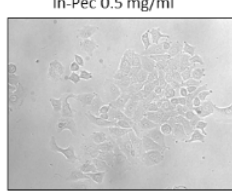

ТВH $75 \mu \mathrm{M}$

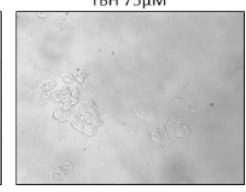

BH 75 MM $+1 \mathrm{n}-\mathrm{Pec}-\mathrm{Hs} 0.5 \mathrm{mg} / \mathrm{m}$

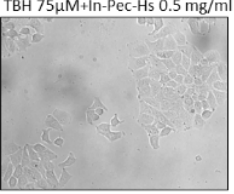

In-Pec-Hs $0.5 \mathrm{mg} / \mathrm{ml}$

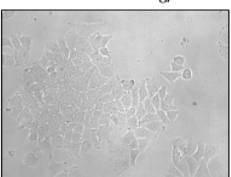

C

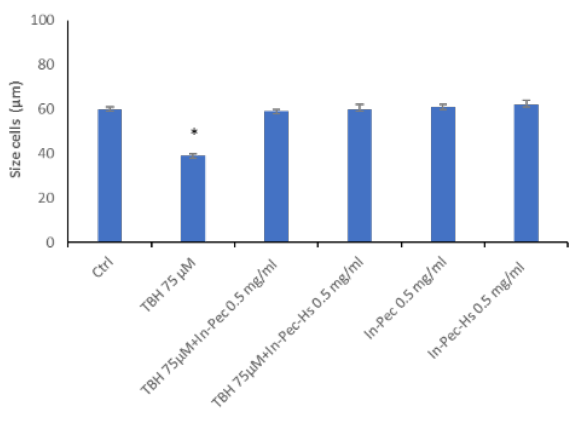

Figure 5. TBH-induced stress on A549 human epithelial cells (A,top), and stress inhibition due to both integral lemon pectin Int-Pec (A, middle) and heat-stressed lemon pectin Int-Pec-Hs (A, bottom) in $0.5 \mathrm{mg} / \mathrm{mL}$ concentration; microscopic observations $(\mathrm{B}$, Bar $=100 \mu \mathrm{m})$ and cell size of the TBH-induced altered cells following addition of each pectin in $0.5 \mathrm{mg} / \mathrm{mL}$ concentration (C).

After $24 \mathrm{~h}$ of incubating the A549 cells with TBH alone or in combination with Int-Pec or Int-Pec-Hs, both the Int-Pec and Int$\mathrm{Pec}-\mathrm{Hs}$ were found to be able to inhibit $\mathrm{TBH}$-induced stress (Figure $5 \mathrm{~A}$ ). The results were also confirmed by microscopic observation (Figures $5 \mathrm{~B}$ and $5 \mathrm{C}$ ) in which a significant recovery of the $\mathrm{TBH}$-induced altered cell morphology and size was observed.

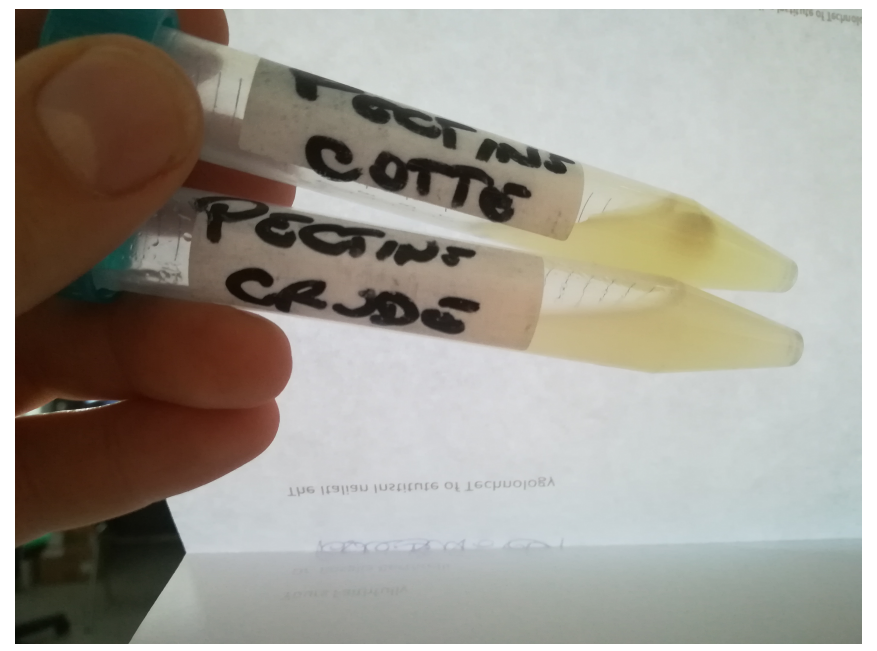

Figure 6. Integral lemon pectin (crude), and heat-stressed integral pectin (cotte) after two-week incubation in phosphate-buffered saline solution.

These results suggest that the coexisting bioactive components in the integral pectin obtained via hydrodynamic cavitation of waste lemon peel from organically grown lemon fruits in Sicily remain viable even after the application of a significant heat stress.
Only the strong antimicrobial activity of limonene [17] is diminished by the thermal treatment. Indeed, as shown in Figure 6 , after incubating for 2 weeks both the integral lemon pectin Int$\mathrm{Pec}$ and the heat-stressed pectin Int-Pec-Hs with the PBS buffered solution, mold formation is observed only for the heatstressed pectin. As expected, this suggests that the amount of terpenes in the newly $\mathrm{HC}$-extracted pectin diminishes after the pectin thermal treatment at $200{ }^{\circ} \mathrm{C}$. A thorough study of the antimicrobial activity of the newly developed Integro-Pectin is in course and results will be reported in due course.

In conclusion, integral lemon pectin obtained for the first time via hydrodynamic cavitation of waste lemon peel in water directly at pre-industrial scale (34 kg of peel in $120 \mathrm{~L}$ water) exerts a significant antioxidant activity, while showing no toxic effects on human epithelial cells even at the remarkably high concentration of $1 \mathrm{mg} / \mathrm{mL}$.

Indeed, scholars in Japan reported as early as of 1998 that lemon flavonoid compounds in lemon juice obtained by an in-line extractor at a juice factory are more abundant than that obtained by hand-squeezing, and are stable even under heat treatment conditions $\left(121^{\circ} \mathrm{C}, 15 \mathrm{~min}\right)$ in acidic solution [18].

Well known for their powerful antioxidant activity, the flavonoid glycosides in the peel of lemon fruit include six flavanon glycosides (eriocitrin, neoeriocitrin, narirutin, naringin, hesperidin, and neohesperidin), and three flavone glycosides (diosmin, 6,8di- $C$ - $\beta$-glucosyldiosmin (DGD), and $6-C$ - $\beta$-glucosyldiosmin (GD). Eriocitrin, neoeriocitrin and DGD show higher antioxidant activity, in comparison to the other biophenols [18]. Furthermore, eriocitrin especially abundant in lemons (and scarce in other citrus fruits) and its metabolites by intestinal bacteria has stronger antioxidative activity than a-tocopherol in the lowdensity lipoprotein oxidation system [19]. 
Since lemon flavonoids are also well known to exert antiinflammatory activity through several mechanisms, from antioxidant and radical scavenging activities through modulation of the production of other proinflammatory molecules and of proinflammatory gene expression [20], the results of experiments aimed to evaluate the anti-inflammatory of the newly obtained lemon pectin will be reported soon.

These results open the route to the development of a number of new, integral pectin-based nutraceutical formulations based on the simple, low cost, scalable and efficient hydrodynamic cavitation extraction process applied to waste lemon peel suspended in water, while meeting all the principles of natural product green extraction $[8,9]$.

\section{Acknowledgements}

This work is dedicated to the memory of Dr Giuseppe 'Beppe' Albeggiani, biologist and gentleman, for all he has done at Palermo's biology Institute of developmental biology of Italy's National Research Council. Thanks to Campisi Citrus, Siracusa, Italy, for the gift of waste lemon peel used for this study. We thank Professors Laura M. Ilharco, Instituto Superior Técnico, University of Lisboa, and Alexandra Fidalgo Instituto Superior Técnico and Universidade Europeia, for prolonged collaboration on our studies devoted to pectin.

\section{Author Information}

\section{ORCID}

Domenico Nuzzo: 0000-0002-4325-417X

Laura Cristaldi: 0000-0002-9888-526X

Marzia Sciortino: 0000-0002-2805-4452

Lorenzo Albanese: 0000-0002-4549-8514

Antonino Scurria: 0000-0001-5624-6833

Federica Zabini: 0000-0003-1505-0839

Claudia Lino: 0000-0002-8724-7772

Mario Pagliaro: 0000-0002-5096-329X

Francesco Meneguzzo: 0000-0002-5952-9166

Marta Di Carlo: 0000-0002-7934-1275

Rosaria Ciriminna: 0000-0001-6596-1572

[1] R. Ciriminna, A. Fidalgo, R. Delisi, L. M. Ilharco, M. Pagliaro, Pectin Production and Global Market, Agro Food Ind. Hi Tech 2016, 27(5), 1720.

[2] R. Ciriminna, N. Chavarría-Hernández, A. Rodríguez Hernández, M. Pagliaro, Pectin: A New Perspective from the Biorefinery Standpoint, Biofuel. Biopr. Bioref. 2015, 9, 368-377.

[3] M. Y. Sayah, R. Chabir, H. Benyahia, Y. Rodi Kandri, F. Ouazzani Chahdi, H. Touzani, F. Errachidi, Yield, Esterification Degree and Molecular Weight Evaluation of Pectins Isolated from Orange and Grapefruit Peels under Different Conditions, PLoS One 2016, 11(9): e0161751.

[4] C. Lara-Espinoza, E. Carvajal-Millán, R. Balandrán-Quintana, Y. LópezFranco, A. Rascón-Chu, Pectin and Pectin-Based Composite Materials: Beyond Food Texture, Molecules 2018, 23(4): 942.

[5] A. S. Matharu, J. A. Houghton, C. Lucas-Torres, A. Moreno, Acid-free microwave-assisted hydrothermal extraction of pectin and porous cellulose from mango peel waste - towards a zero waste mango biorefinery, Green Chem. 2016, 18, 5280-5287.

[6] H. Xia, A. S. Matharu, Unavoidable food supply chain waste: acid-free pectin extraction from mango peel via subcritical water, Faraday Discuss. 2017, 202, 31-42.

[7] R. Ciriminna, A. Fidalgo, D. Carnaroglio, G. Cravotto, G. Grillo, A. Tamburino, L. M. Ilharco, M. Pagliaro, Eco-Friendly Extraction of Pectin and Essential Oils from Orange and Lemon Peels, ACS Sust. Chem. Eng. 2016, 4, 2243-2251.

[8] F. Meneguzzo, F. Zabini, L. Albanese, A. Crisci, Novel Affordable, Reliable and Efficient Technologies to Help Addressing the WaterEnergy-Food Nexus, Eur. J. Sustain. Dev. 2019, 8:1-17.

[9] F. Meneguzzo, C. Brunetti, A. Fidalgo, R. Ciriminna, R. Delisi, L. Albanese, F. Zabini, A. Gori, L. B. dos Santos Nascimento, A. De Carlo, F. Ferrini, L. M. Ilharco, M. Pagliaro, Real-Scale Integral Valorization of Waste Orange Peel via Hydrodynamic Cavitation, Processes 2019, 7: 581.

[10] S. Zhao, F. Yang, Y. Liu, D. Sun, Z. Xiu, X. Ma, Y. Zhang, G. Sun, Study of chemical characteristics, gelation properties and biological application of calcium pectate prepared using apple or citrus pectin, Int. J. Biol. Macromol. 2018, 109, 180-187.

[11] (a) D. Nuzzo, M. Contardi, D. Kossyvaki, P. Picone, L. Cristaldi, G. Galizzi, G. Bosco, S. Scoglio, A. Athanassiou, M. Di Carlo, HeatResistant Aphanizomenon flos-aquae (AFA) Extract (Klamin $®$ ) as a Functional Ingredient in Food Strategy for Prevention of Oxidative Stress, Oxid. Med. Cell. Longev. 2019, 2019:9481390; (b) D. Nuzzo, G. Presti, P. Picone, G. Galizzi, E. Gulotta, S. Giuliano, C. Mannino, V. Gambino, S. Scoglio, M. Di Carlo Effects of the Aphanizomenon flosaquae Extract (Klamin $囚$ ) on a Neurodegeneration Cellular Model, Oxid. Med. Cell. Longev. 2018, 2018:9089016.

[12] (a) P. Ninfali, A. Chiarabini, D. Angelino, The ORAC/kcal ratio qualifies nutritional and functional properties of fruit juices, nectars, and fruit drinks, Int. J. Food Sci. Nutr. 2014, 65, 708-712; (b) G. Cao, H. M. Alessio, R. G. Cutler, Oxygen-radical absorbance capacity assay for antioxidants, Free Radic. Biol. Med. 1993, 14, 303-311.

[13] C. M. Bitler, T. M. Viale, B. Damaj, R. Crea, Hydrolyzed Olive Vegetation Water in Mice Has Anti-Inflammatory Activity, J. Nutr. 2005, 135, 1475-1479.

[14] S. Y. Wang, H. S. Lin, Antioxidant activity in fruits and leaves of blackberry, raspberry, and strawberry varies with cultivar and developmental stage, J. Agric. Food Chem. 2000, 48, 140-146.

[15] K. A. Foster, C. G. Oster, M. M. Mayer, M. L. Avery, K. L. Audus, Characterization of the A549 Cell Line as a Type II Pulmonary Epithelial Cell Model for Drug Metabolism, Exp. Cell Res. 1998, 243, 359-366.

[16] K. Abe, H. Saito, Characterization of $t$-Butyl Hydroperoxide Toxicity in Cultured Rat Cortical Neurones and Astrocytes, Pharmacol. Toxicol. 1998, 83, 40-46.

[17] R. Ciriminna, M. Lomelli, P.. Demma Carà, J. Lopez-Sanchez, M. Pagliaro, Limonene: A Versatile Chemical of the Bioeconomy, Chem. Commun. 2014, 50, 15288-15296.

[18] Y. Miyake, K. Yamamoto, Y. Morimitsu, T. Osawa, Characteristics of Antioxidative Flavonoid Glycosides in Lemon Fruit, Food Sci. Technol. Int. 1998, 4, 48-53.

[19] Y. Miyake, K. Yamamoto, Y. Morimitsu, T. Osawa, Isolation of CGlucosylflavone from Lemon Peel and Antioxidative Activity of Flavonoid Compounds in Lemon Fruit, J. Agric. Food Chem. 1997, 45, 4619-4623.

[20] A. García-Lafuente, E. Guillamón, A. Villares, A. Mauricio, R. Jose, Martínez A., A. Martínez, Flavonoids as anti-inflammatory agents: implications in cancer and cardiovascular disease, Inflamm. Res. 2009, $58,537-552$. 
Exceptional antioxidant, non-cytotoxic activity of integral lemon pectin from hydrodynamic cavitation

D. Nuzzo, L. Cristaldi, M. Sciortino, L. Albanese, A. Scurria, F. Zabini, C. Lino, M. Pagliaro, F. Meneguzzo, M. Di Carlo, R. Ciriminna

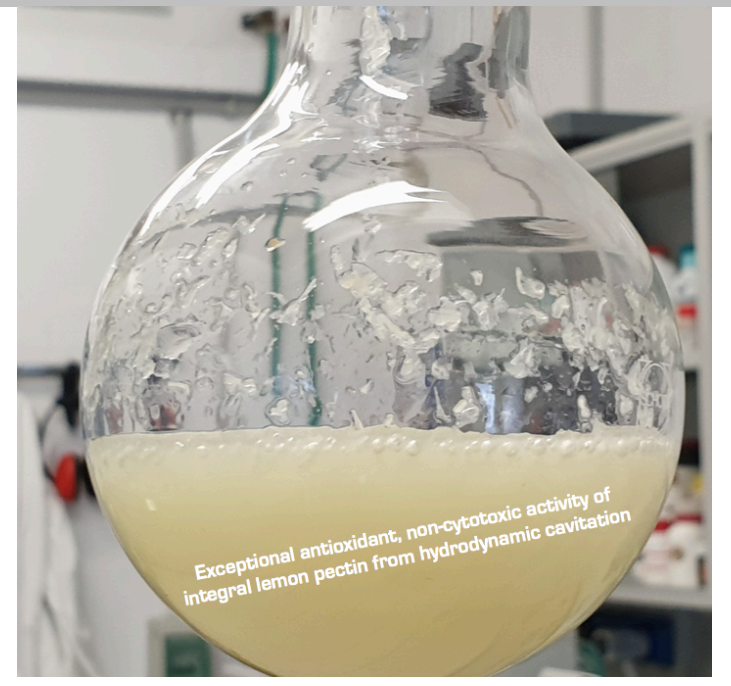

